\title{
Qualitative assessment of Tongue Drive System by people with high-level spinal cord injury
}

\author{
Jeonghee Kim, MS; ${ }^{1}$ Hangue Park, MS; ${ }^{1}$ Joy Bruce, MSPT, PhD $;^{2}$ Diane Rowles, MS, NP; ${ }^{3}$ Jaimee Holbrook, \\ MD ${ }^{4}$ Beatrice Nardone, MD, PhD; ${ }^{4}$ Dennis P. West, PhD; ${ }^{4}$ Anne E. Laumann, MBChB, MRCP (UK); ${ }^{4-5}$ Elliot \\ Roth, MD; $;^{3,5}$ Emir Veledar, PhD; ${ }^{6}$ Maysam Ghovanloo, PhD $^{1^{*}}$ \\ ${ }^{1}$ GT Bionics Laboratory, School of Electrical and Computer Engineering, Georgia Institute of Technology, Atlanta, \\ GA; ${ }^{2}$ Shepherd Center, Atlanta, GA; Departments of ${ }^{3}$ Physical Medicine and Rehabilitation and ${ }^{4}$ Dermatology, Fein- \\ berg School of Medicine, Northwestern University, Chicago, IL; ${ }^{5}$ Rehabilitation Institute of Chicago, Chicago, IL; \\ ${ }^{6}$ School of Medicine, Emory University, Atlanta, GA; and Baptist Health South Florida, Miami, FL
}

\begin{abstract}
The Tongue Drive System (TDS) is a minimally invasive, wireless, and wearable assistive technology (AT) that enables people with severe disabilities to control their environments using tongue motion. TDS translates specific tongue gestures into commands by sensing the magnetic field created by a small magnetic tracer applied to the user's tongue. We have previously quantitatively evaluated the TDS for accessing computers and powered wheelchairs, demonstrating its usability. In this study, we focused on its qualitative evaluation by people with high-level spinal cord injury who each received a magnetic tongue piercing and used the TDS for $6 \mathrm{wk}$. We used two questionnaires, an after-scenario and a poststudy, designed to evaluate the tongue-piercing experience and the TDS usability compared with that of the sip-and-puff and the users' current ATs. After study completion, $73 \%$ of the participants were positive about keeping the magnetic tongue-barbell in order to use the TDS. All were satisfied with the TDS performance and most said that they were able to do more things using TDS than their current ATs (4.22/5).
\end{abstract}

Clinical Trial Registration: ClinicalTrials.gov; "Evaluation of a tongue operated assistive technology for individuals with severe paralysis (TDS-1)"; NCT01124292;

http://clinicaltrials.gov/ct2/show/NCT01124292
Key words: assistive technologies, computer access, magnetic tongue piercing, qualitative analysis, questionnaire, rehabilitation, spinal cord injury, tetraplegia, tongue drive, wheelchair navigation.

\section{INTRODUCTION}

According to a report from the Christopher and Dana Reeve Foundation, 1 in 50 individuals are living with a form of motor disability resulting from stroke, spinal cord injury (SCI), multiple sclerosis, cerebral palsy, postpolio

\footnotetext{
Abbreviations: $\mathrm{AQ}=\mathrm{ASQ}$ question, $\mathrm{ASQ}=$ after-scenario questionnaire, $\mathrm{AT}=$ assistive technology, $\mathrm{BCI}=$ brain-computer interface, $\mathrm{C}=$ cervical, eTDS $=$ external TDS, iTDS $=$ intraoral TDS, NU = Northwestern University, $\mathrm{PC}=$ personal computer, $\mathrm{PQ}=$ PSSUQ question, PSSUQ = poststudy system usability questionnaire, $\mathrm{PWC}=$ powered wheelchair, $\mathrm{SCA}=$ Shepherd Center in Atlanta, $\mathrm{SCI}=$ spinal cord injury, $\mathrm{SnP}=$ sip-and-puff, TDS $=$ Tongue Drive System.

*Address all correspondence to Maysam Ghovanloo, PhD; School of Electrical and Computer Engineering, Georgia Institute of Technology, 85 Fifth St NW, TRSB-419, Atlanta, GA 30308; 605-644-6826; fax: 404-894-4701. Email: $\underline{\text { mgh@gatech.edu }}$ http://dx.doi.org/10.1682/JRRD.2013.08.0178
} 
syndrome, or traumatic brain injury [1]. With a strong desire to improve their quality of life, individuals with severe disabilities and their family members are interested in novel assistive technologies (ATs) [2]. Even though a number of ATs, such as brain-computer interfaces (BCIs); electromyography (EMG) switches; speech recognition software; and head-array, eye-tracker, and sip-and-puff (SnP) switches, have been around for a while, people with severe disabilities, such as tetraplegia, have very limited options [2]. Despite this, the rate of AT abandonment is surprisingly high (35-75\%) [3]. Reasons cited include poor performance, not meeting users' needs or preferences, low reliability, difficulty in using the device, complex maintenance, poor customer support, stigmatizing aesthetics, and environmental barriers [4-5]. In order to design and develop efficacious, user-friendly, and acceptable ATs that will eventually leave the research laboratory, detailed consideration of both quantitative and qualitative aspects of a new technology, especially from the perspective of the end user, is necessary [6-8].

The Tongue Drive System (TDS) is a wireless and wearable AT for people with severe disabilities [9-10]. It is meant to help them access personal computers (PCs), drive powered wheelchairs (PWCs), and control environments using free, voluntary tongue motion (Figure 1). It translates specific user-defined tongue gestures into application-specific commands by detecting the position of a small magnetic tracer on the user's tongue. The magnetic tracer can be either directly glued on the tongue for temporary use (e.g., screening) or embedded in a titanium tongue-barbell and attached to the tongue via piercing [11]. The prototype used in these studies consists of a headgear that holds magnetic sensors near the cheeks of the user on a pair of goosenecks, which facilitate their positioning. Sensors are sampled at $50 \mathrm{~Hz}$, and the raw data are transmitted wirelessly to a PC or smartphone (iPhone, Apple; Cupertino, California) at $2.4 \mathrm{GHz}$ [11]. A real-time sensor signal processing algorithm, running on the PC/smartphone, cancels the external magnetic interference and detects tongue positions for up to six userdefined commands plus its neutral/resting position [12].

In previous studies, we analyzed the speed and accuracy of nondisabled and tetraplegic participants accessing PCs, smartphones, and PWCs using TDS and compared their performances with traditional computer input devices and joysticks $[10,13]$. We have reported the

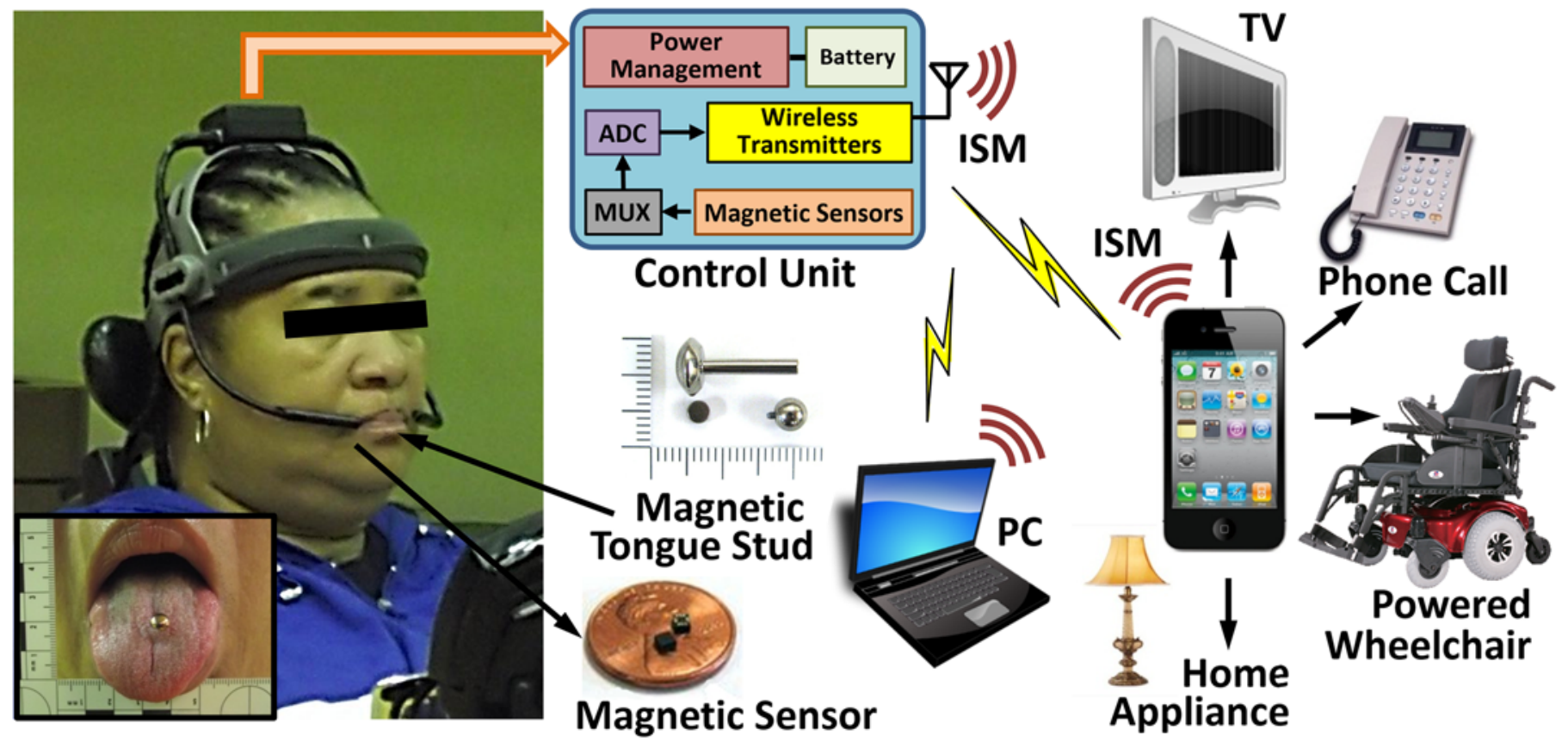

Figure 1.

Block diagram of Tongue Drive System. $\mathrm{ADC}=$ analog to digital converter, ISM = industrial-scientific-medical band, $\mathrm{MUX}=$ multiplexer, $\mathrm{PC}=$ personal computer. 
learning effects over five sessions, suggesting the potential for further improvements over time [14-15]. Herein, we report the results of a qualitative study on a group of potential TDS end users with high-level SCI, seeking their opinions about the acceptability of this new AT during and after a 6 wk usability study.

\section{METHODS}

\section{Demography and Assistive Devices}

Twenty-one individuals with tetraplegia from SCI were enrolled in a $6 \mathrm{wk}$, dual-center trial to assess the usability of the TDS after receiving a magnetic tongue piercing. All participants provided informed consent to the procedures approved by the institutional review boards of record at Shepherd Center in Atlanta (SCA) and Northwestern University (NU) in Chicago. Ten participants dropped out at different stages of the trial because of disqualification during screening, loss of interest, noncompliance with scheduled study visits, losing the tongue barbell, transportation difficulties, and medical issues unrelated to this study.

Eleven participants, 9 male and 2 female $(38.6 \pm$ 9.8 yr old; range: $27-56 \mathrm{yr}$ ), completed the study and the questionnaires. Participants' demography is shown in Figure 2. Seven were enrolled in SCA and four at NU. All participants qualified for alternative control, with SCI levels between cervical (C)2 and C6 (Figure 2(c)). Postinjury duration was between 3.4 to $24.7 \mathrm{yr}$ (mean: $12.1 \pm 7.3 \mathrm{yr}$ ) (Figure 2(d)). All participants drove PWCs on a daily basis using either an $\mathrm{SnP}(54.5 \%)$ or a modified joystick (45.5\%). Of the participants, 36.4 percent did not use computers on a regular basis, 36.4 percent (with C5 and (a)

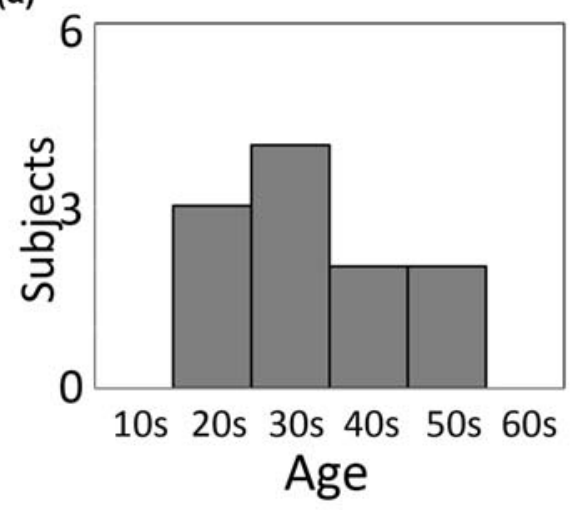

(d)

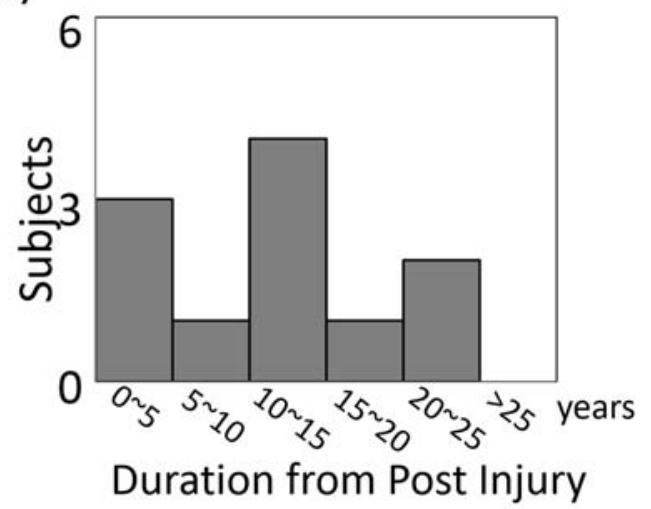

(b)

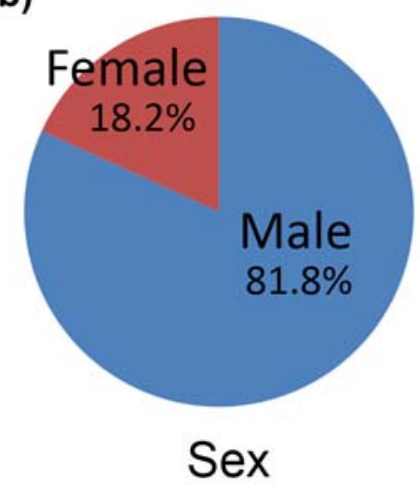

(e)

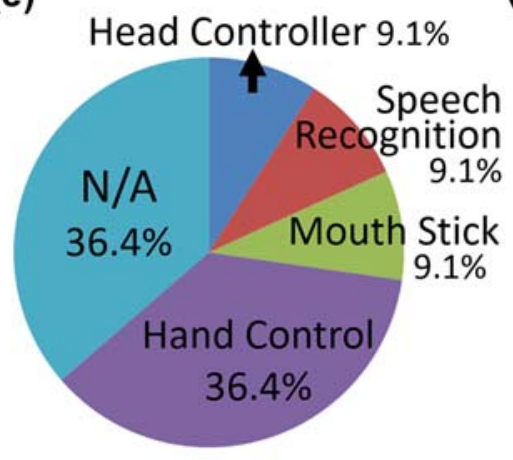

AT for PC (c)

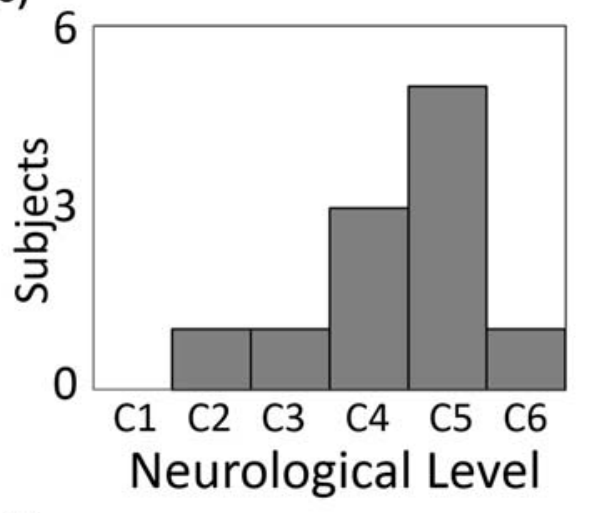

(f)

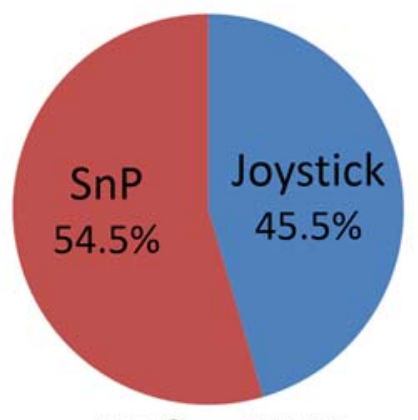

AT for PWC

Figure 2.

Participants' demography: (a) age, (b) sex, (c) level of injury, (d) duration postinjury in years, and current assistive technology (AT) for (e) personal computer (PC) access and (f) powered wheelchair (PWC) navigation. $C=$ cervical, N/A = not applicable, SnP = sip-andpuff. 
C6 SCI) had some limited hand motion, and 36.4 percent used other ATs, such as a mouth stick, head controller, or speech recognition software.

\section{Questionnaire Design}

Key parts of the questionnaire were designed to explore the tongue-piercing experience and the ongoing usability of the TDS compared with SnP and participants' current ATs. At the end of each PC access and PWC navigation session, participants were asked 9 and 13 questions, respectively, related to the cognitive load and usability of the TDS with respect to these tasks, referred to as the after-scenario questionnaires (ASQs) [16]. At the end of the study, a comprehensive 75-question poststudy system usability questionnaire (PSSUQ) was administered [16-17]. This included factors related to the piercing experience, TDS accessibility, usability, satisfaction, and comparison with other ATs. The majority of questions in both ASQ and PSSUQ were designed on a 5point Likert-type scale. PSSUQ also included two polar (Yes-No) and four open-ended questions.

Figure 3 shows the study flowchart. Following enrollment, participants were evaluated physically for intraoral anatomy, tongue motion, and cognitive capability for using the TDS. This was followed by screening sessions using magnetic tracers temporarily glued on the

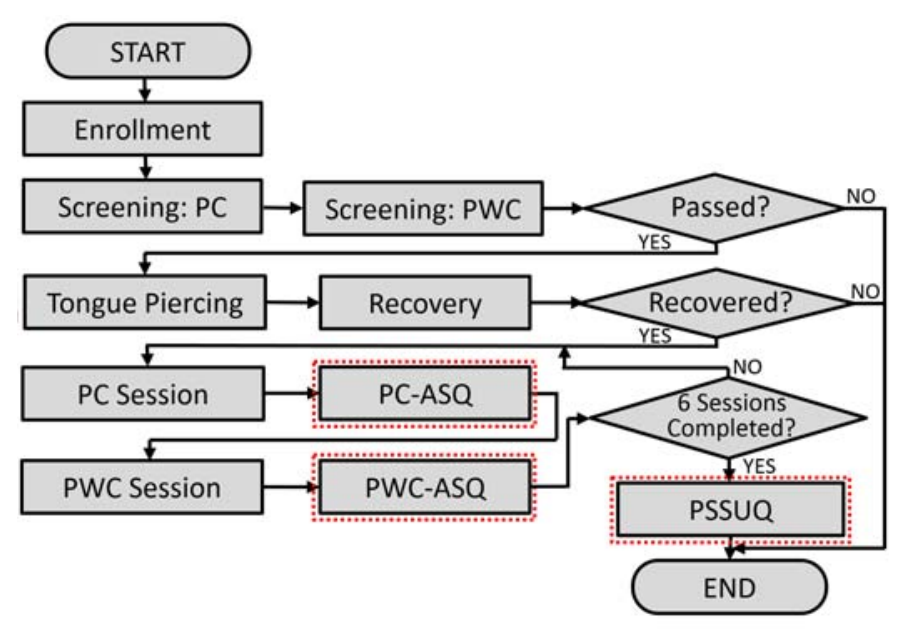

Figure 3.

Flowchart of Tongue Drive System trials and administration of questionnaires. $\mathrm{ASQ}=$ after-scenario questionnaire, $\mathrm{PC}=$ personal computer, PSSUQ = poststudy system usability questionnaire, $\mathrm{PWC}=$ powered wheelchair. tongue to operate the TDS for PC access and PWC navigation. Participants who passed screening received tongue piercing by a physician [18]. After $4 \mathrm{wk}$, the temporary standard tongue-barbell with a long post was exchanged for a shorter, more closely fitting barbell with a magnetic tracer embedded in the upper ball. Participants then underwent one PC access and one PWC navigation session each week for six consecutive weeks. Each session was followed by an ASQ. At the end of the last session, instead of a PWC-ASQ, a PSSUQ was administered. This article reports results from ASQs for the first $5 \mathrm{wk}$ and a subset of the PSSUQ responses.

\section{Data Analysis}

Factor analysis is a statistical procedure that examines the correlations among variables to discover clusters of related variables [16]. Statistical analysis using factor analysis with varimax-rotated solutions was performed to achieve factor loadings, which verified the relationship between questions and factors. Factor loadings $\geq 0.5$ indicate a meaningful relationship. We estimated the reliability of the questions using the coefficient alpha $(\alpha)$, which should be $>0.7$ [16]. Repeated measure analysis of variance was used in the statistical analysis of the repeated ASQ results to calculate the $p$-value between the first and fifth sessions $\left(p_{1-5}\right)$. This analysis was conducted using SPSS (SPSS v21, IBM Corporation; Armonk, New York). Statement-by-statement qualitative analysis was also conducted [19].

\section{RESULTS}

\section{Tongue Piercing}

Participants were asked seven questions related to tongue piercing in the PSSUQ, summarized in Figure 4 and categorized as four factors, accounting for 90.9 percent of the total variance via factor analysis. Responses are summarized in Figure 5. The factor loadings for the first factor (pain and piercing) associated with PSSUQ question (PQ)1 and PQ2 were calculated as 0.95 and 0.94, respectively, with $\alpha=0.90$. Of the participants, 70 percent stated that the tongue piercing was not painful (PQ1: $3.82 \pm 1.40$, PQ2: $4.18 \pm 1.33$ ), while less than 20 percent of subjects said that they experienced some level of pain from the piercing procedure. 
PQ1. How was your tongue piercing experience?

1) Very painful, 5) Not painful

PQ2. Was your tongue piercing experience more painful than what you expected?

1) Very much so, 3) About the same as what I expected, 5) Not at all

PQ3. Would you be willing to keep wearing a tongue piercing in order to use the TDS?

1) No, 3) Maybe, 5) Yes

PQ4. Are you going to keep wearing jewelry on your tongue?

1) No, 3) Maybe, 5) Yes

PQ5. How did other people react to your tongue stud?

1) Negative, 3) Did not notice it, 5) Positive

PQ6. Did anyone make specific comments about the design (appearance) of the magnetic tongue stud? 1) No, 2)Yes

PQ7. How clear were the instructions you were given after tongue piercing?

1) Not at all clear, 3) Neither clear nor unclear, 5) Very clear

Figure 4.

Questions related to tongue piercing experience. PQ = poststudy system usability questionnaire question, TDS = Tongue Drive System.
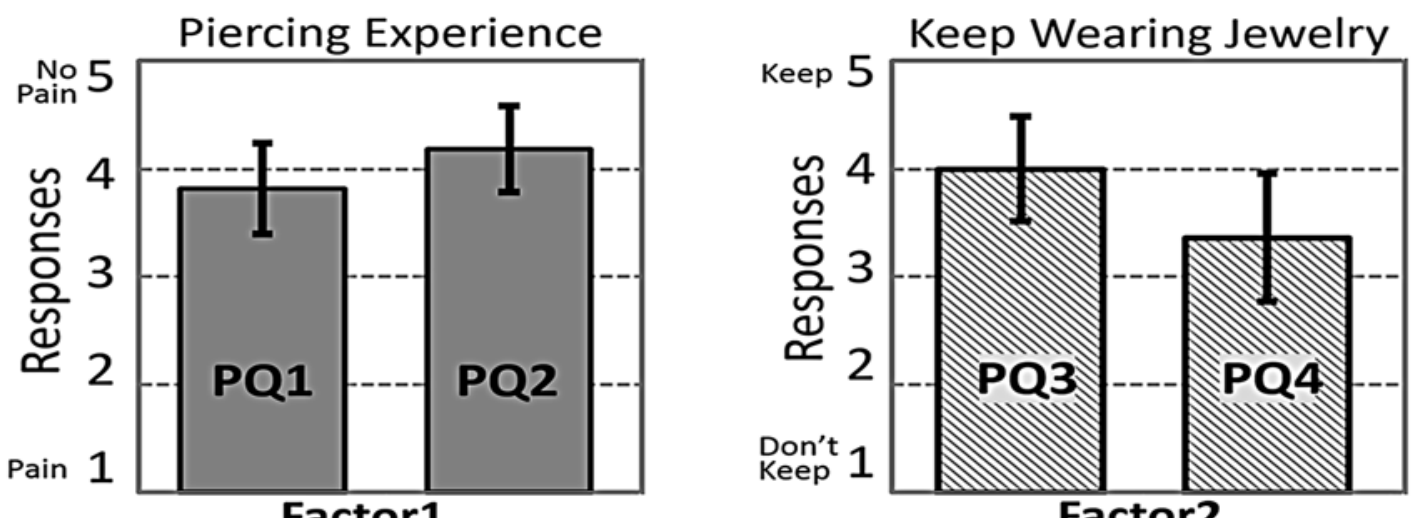

Factor1

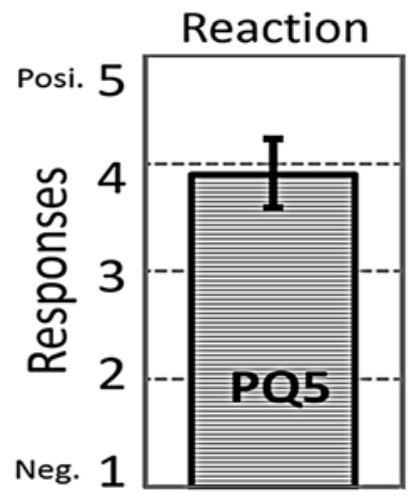

Comments from Others

Factor2

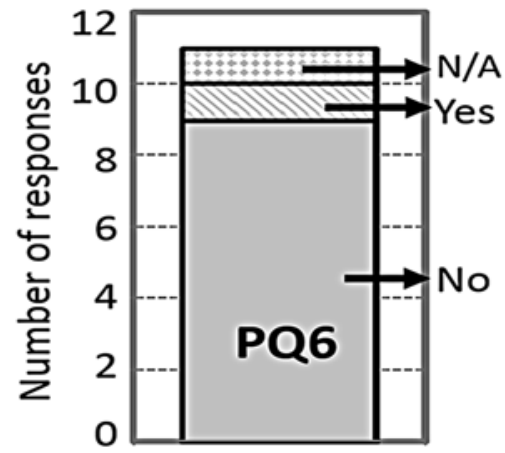

Factor3

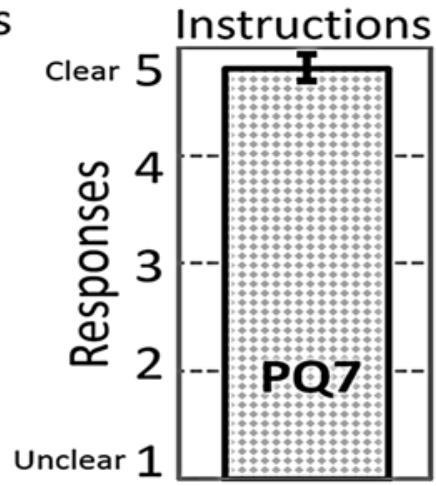

Factor4

Figure 5.

Participants' responses to questions related to tongue piercing (Figure 4) in 5-point Likert scale. Error bars represent standard error. $\mathrm{PQ}=$ poststudy system usability questionnaire question. 
The second factor related to the participants' desire to keep wearing a tongue barbell. The factor loadings for PQ3 and PQ4 were 0.87 and 0.85 , respectively $(\alpha=$ $0.72)$. Six subjects $(55 \%)$ wanted to keep their tongue piercing (PQ4: $3.36 \pm 1.96)$, while eight subjects $(73 \%)$ would have wanted to maintain it in order to use the TDS (PQ3: $4.00 \pm 1.61$ ) if TDS were available and supported following the trial.

The third factor was the reaction of other people to the participants' tongue piercing. The factor loading was 0.87 and 0.81 for PQ5 and PQ6, respectively, with $\alpha=$ 0.37 . Seven out of 11 participants $(63.6 \%)$ said that other people reacted positively to the tongue piercing, and three of them $(27.3 \%)$ said that no one seemed to have noticed it. Similarly, 9 out of 11 participants (81.8\%) answered that no one had made any specific comments about the tongue barbell.

The fourth factor related to the clarity of the instructions given before/after piercing (PQ7). The factor loading was 0.99 , but we could not estimate $\alpha$ from one question. Nine subjects $(82 \%)$ stated that the instructions were clear (average score: $4.82 \pm 0.40$ ).

\section{System Accessibility}

Participants were asked five questions related to system accessibility (Figure 6). The responses are illustrated in Figure 7. Three factors accounted for 98.0 percent of the total variance. The factor loadings for the first factor (PQ8 and PQ9) were 0.85 and 0.71 , respectively $(\alpha=$ $0.94)$. Out of 11 participants, $8(72.7 \%)$ answered "No" to the question about having concerns about the headgear appearance, and 7 out of 11 subjects $(63.6 \%)$ responded that they did not worry about it (PQ9: $3.63 \pm 1.91)$. The factor loadings for the second factor (PQ10 and PQ11) were 0.84 and 0.83 , respectively $(\alpha=0.94)$. Of the subjects, 63.6 percent responded that the system calibration was very easy $(4.36 \pm 0.92)$ and 45.5 percent found the training procedures were very easy $(4.09 \pm 1.04)$ [13] The factor loading for the third factor was 0.85 , which was related to the instructions given mostly during the first screening session. Of the 11 participants, 9 said that the instructions to learn the TDS were very clear (4.82 \pm $0.41)$.

\section{Tongue Drive System Performance and Learning} Eight ASQ questions (AQs) in Figure 8 were categorized in four factors, accounting for 67.0 percent of total variance, and the results are depicted in Figure 9. The first factor related to the cognitive loading of the TDS in $\mathrm{PC}$ access and PWC navigation (AQ1 and AQ2). The factor loadings were 0.86 and 0.75 , respectively, and $\alpha=$ 0.80 . In the first session, participants reported a medium level of cognitive loading to issue TDS commands for both PC and PWC (AQ1: $2.91 \pm 1.39$, AQ2: $3.18 \pm 1.25$ ). However, the scores increased significantly over five sessions and reached AQ1: $4.27 \pm 0.90\left(p_{1-5}<0.01\right)$ and AQ2: $4.09 \pm 0.83\left(p_{1-5}=0.02\right)$ in the fifth session (Figure 9(a)).

The second factor was related to the speed of cursor on the PC screen or PWC motion on the obstacle course. AQ3 had factor loading of 0.83 , and participants generally stated that the speed of mouse cursor was "just right" over all five sessions. However, they felt that the speed of PWC was too slow as they learned various PWC control strategies using the TDS (factor loading $=-0.47$ ). Thus, the average score for AQ4 was reduced from $2.70 \pm 0.67$ in the first session to $2.27 \pm 1.01$ in the fifth session (Figure 9(b)).

\begin{tabular}{|c|c|}
\hline PQ9. & $\begin{array}{l}\text { Were you concerned how it looked to others? } \\
\text { 1) Yes, 5) No } \\
\text { How worried were you about how the headgear looked to others? } \\
\text { 1) Very concerned, 5) Not at all concerned }\end{array}$ \\
\hline PQ10. & $\begin{array}{l}\text { Were the setup and calibration of the TDS? } \\
\text { 1) Too complicated, 5) Very easy }\end{array}$ \\
\hline PQ11. & $\begin{array}{l}\text { Was the procedure to train the TDS to recognize the tongue commands? } \\
\text { 1) Difficult, 3) Neither difficult nor easy, 5) Easy }\end{array}$ \\
\hline PQ12. & $\begin{array}{l}\text { How clear were the instructions you were given when learning to use the TDS? } \\
\text { 1) Not at all clear, 3) Neither clear nor unclear, 5) Very clear }\end{array}$ \\
\hline
\end{tabular}

Figure 6.

Questions related to Tongue Drive System (TDS) usability. PQ = poststudy system usability questionnaire question. 


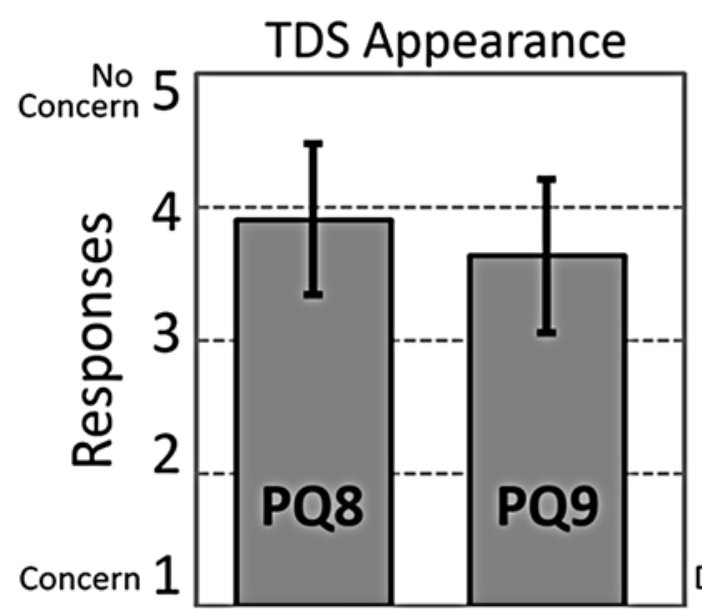

Factor1

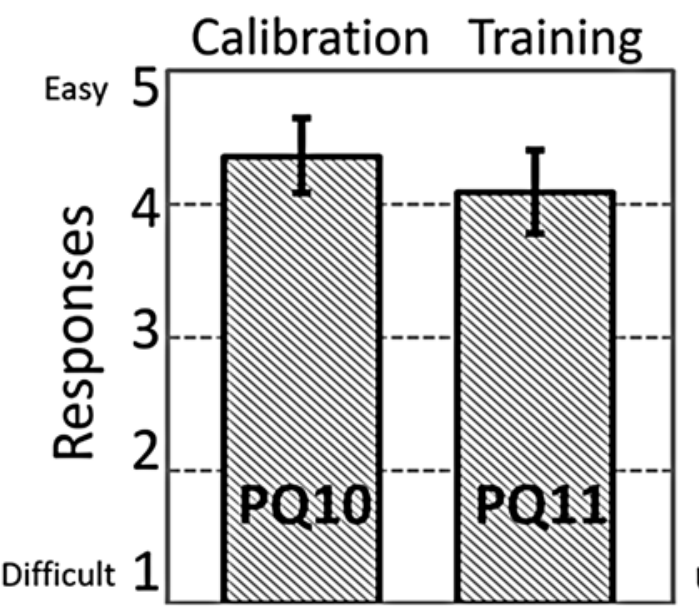

Factor2

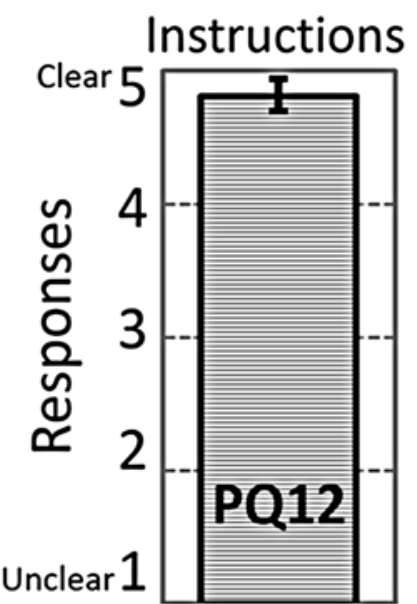

Factor3

Figure 7.

Participants' responses to Tongue Drive System (TDS) usability questions (Figure 6) in 5-point Likert scale. Error bars represent standard error. $\mathrm{PQ}=$ poststudy system usability questionnaire question.

\begin{tabular}{|c|c|}
\hline AQ1. & $\begin{array}{l}\text { How much thought was necessary to decide where to put your tongue to issue a specific } \\
\text { command with the TDS for computer access? }\end{array}$ \\
\hline AQ2. & $\begin{array}{l}\text { How much thought was necessary to decide where to put your tongue to issue a specific } \\
\text { command with the TDS for PWC driving? } \\
\text { 1) A lot, 5) A little }\end{array}$ \\
\hline \multirow{2}{*}{$\begin{array}{l}\text { AQ3. } \\
\text { AQ4. }\end{array}$} & Was the speed of the cursor movement on the computer screen: \\
\hline & $\begin{array}{l}\text { Was the speed of the wheelchair: } \\
\text { 1) Too slow, 3) Just right, 5) Very fast }\end{array}$ \\
\hline AQ5. & $\begin{array}{l}\text { How was pointing on targets on the computer screen with the TDS? } \\
\text { 1)Very difficult, 3) Needed some attention, 5) Very easy }\end{array}$ \\
\hline \multirow{2}{*}{$\begin{array}{l}\text { AQ6. } \\
\text { AQ7. } \\
\text { AQ8. }\end{array}$} & $\begin{array}{l}\text { Guiding the powered wheelchair with TDS unlatched strategy was: } \\
\text { Guiding the powered wheelchair with TDS latched strategy was: }\end{array}$ \\
\hline & $\begin{array}{l}\text { Guiding the powered wheelchair with TDS semi-pro strategy was: } \\
\text { 1)Very difficult, 3) Needed some attention, 5) Very easy }\end{array}$ \\
\hline
\end{tabular}

Figure 8.

Questions related to Tongue Drive System (TDS) performance and learning. $\mathrm{AQ}=$ after-scenario questionnaire question, PWC = powered wheelchair.

The third factor represented by AQ5 was related to the ease of point and click tasks for PC access using the TDS. This revealed a close relationship with the first factor (factor loading $=0.63$ ). Participants felt increasingly more at ease with controlling the cursor on the PC screen using the TDS, with the score beginning at $3.36 \pm 1.12$ in the first session and reaching $4.27 \pm 0.79$ in the fifth session $\left(p_{1-5}=0.04\right)$ (Figure 9(c)).
The fourth factor was related to the TDS usability in PWC navigation with three control strategies: unlatched, latched, and semiproportional (AQ6, AQ7, and AQ8), which are described in Yousefi et al. [15] and Huo and Ghovanloo [20]. The factor loadings were $0.83,0.49$, and 0.63 , respectively $(\alpha=0.49$ ). The scores of the latched strategy had the highest rate of increment, followed by that of the semiproportional (Figure 9(d)). Subjects felt 


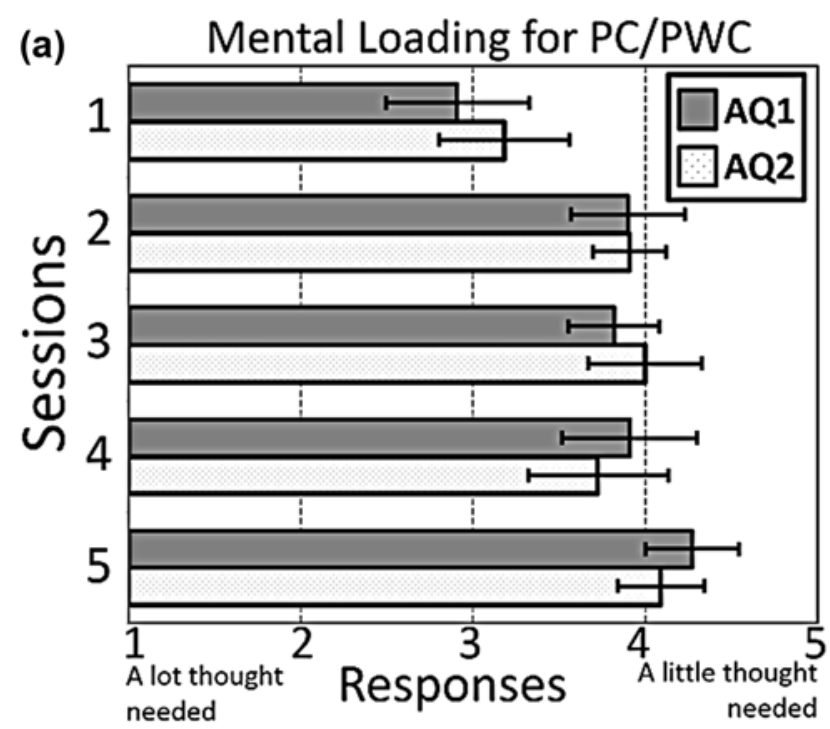

(b)
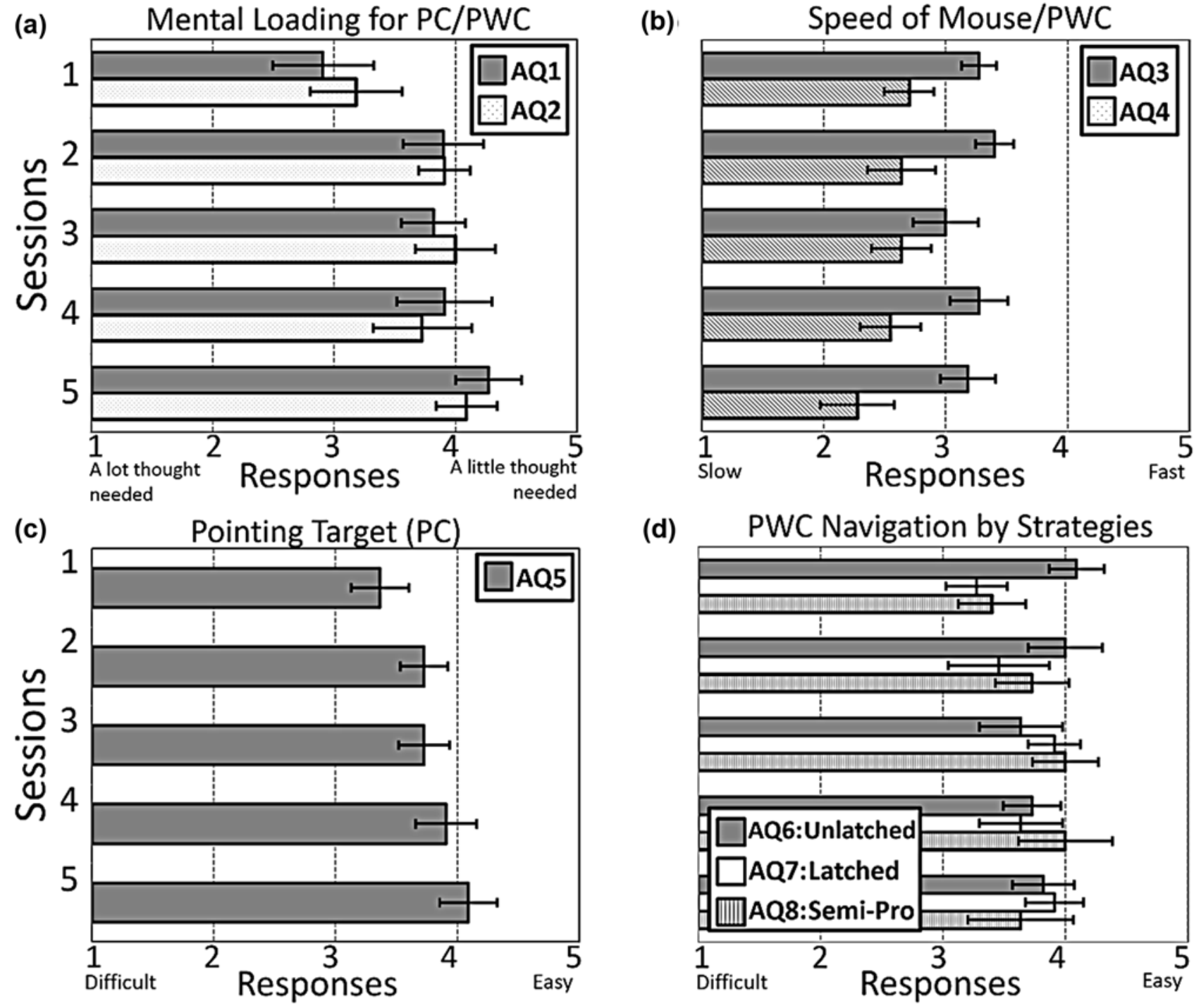

(d)

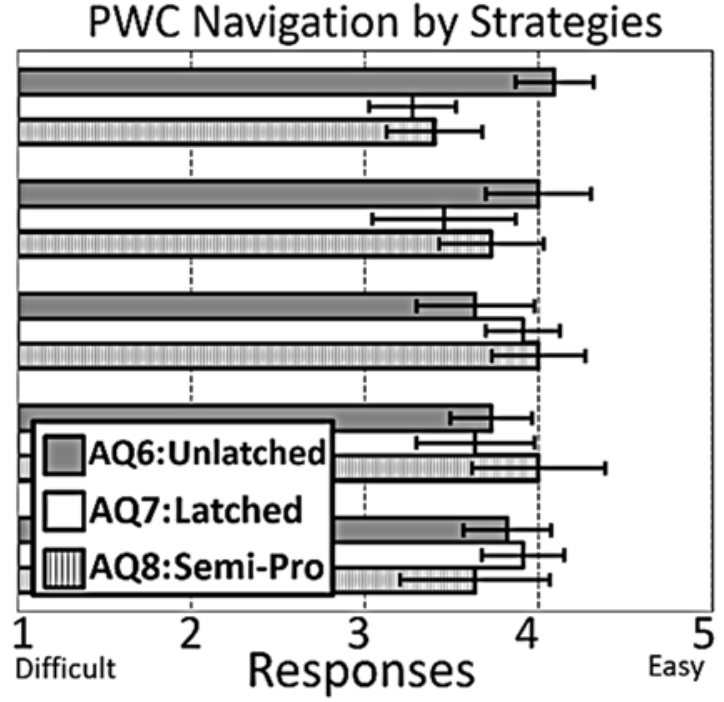

Figure 9.

Participants' responses to questions related to Tongue Drive System performance (Figure 8) over five sessions. Error bars represent standard error. (a) Mental loading for personal computer (PC)/powered wheelchair (PWC). (b) Speed of mouse/PWC. (c) Pointing target (PC). (d) PWC navigation by strategies. AQ = after-scenario questionnaire question.

the unlatched strategy was easy in the first session $(4.10 \pm$ $0.83)$, and this did not change significantly over five sessions $\left(p_{1-5}=0.27\right)$.

\section{Tongue Drive System Performance Compared with Other Assistive Devices}

Another group of questions in the PSSUQ included three factors: usability of the TDS and SnP (ease of use and effectiveness), satisfaction with the TDS, and com- parison between TDS and the current AT, which accounted for 87.3 percent of the total variance. Thirteen questions in this group are summarized in Figure 10, and responses are shown in Figure 11. PQ13 to PQ20 were closely related to the first factor, with factor loadings between 0.69 and 0.96 and $\alpha=0.69$. Odd and even questions were associated with the TDS and SnP, respectively. Questions PQ13 through PQ16 were related to ease of use and questions PQ17 through Q20 were about the 


\begin{tabular}{|c|c|}
\hline $\begin{array}{l}\text { PQ13. } \\
\text { PQ14. } \\
\text { PQ15. }\end{array}$ & $\begin{array}{l}\text { Was it easy to point accurately to targets on computer using TDS? } \\
\text { Was it easy to point accurately to target on computer using SnP? } \\
\text { Was it easy to guide PWC in obstacle course using TDS? }\end{array}$ \\
\hline PQ16. & $\begin{array}{l}\text { Was it easy to guide PWC in obstacle course using SnP? } \\
\text { 1) Very difficult, 3) Needed some attention, 5) Very easy }\end{array}$ \\
\hline PQ17. & Was the TDS effective for using the computer? \\
\hline PQ18. & Was the SnP effective for using the computer? \\
\hline PQ19. & Was the TDS effective for Driving PWC? \\
\hline PQ20. & $\begin{array}{l}\text { Was the SnP effective for Driving PWC? } \\
\text { 1) Completely ineffective, 5) Very effective }\end{array}$ \\
\hline PQ21. & $\begin{array}{l}\text { How satisfied were you with the TDS? } \\
\text { 1) Not at all satisfied, 3) Neither satisfied nor dissatisfied, 5) Very satisfied }\end{array}$ \\
\hline PQ22. & $\begin{array}{l}\text { Would you be willing to use the TDS on a daily basis? } \\
\text { 1) No, not at all, 3) Sometimes, 5) Yes, all the time }\end{array}$ \\
\hline PQ23. & $\begin{array}{l}\text { Compared to your current assistive device, the TDS was: } \\
\text { 1) More difficult to use, 5) Much easier to use }\end{array}$ \\
\hline PQ24. & $\begin{array}{l}\text { Compared to your current assistive device, the TDS was: } \\
\text { 1) Not as effective, 3) About the same, 5) More effective }\end{array}$ \\
\hline PQ25. & $\begin{array}{l}\text { TDS allows you to do things compared to you current AT: } \\
\text { 1) Fewer things, 5) More things }\end{array}$ \\
\hline
\end{tabular}

Figure 10.

Questions related to Tongue Drive System (TDS) usability compared with other assistive technologies. AT = assistive technology, $\mathrm{PQ}=$ poststudy system usability questionnaire question, $\mathrm{PWC}=$ powered wheelchair, $\mathrm{SnP}=$ sip-and-puff.

effectiveness of these devices. TDS and SnP received the same scores in terms of ease of use for PC access (TDS: $4.36 \pm 0.67, \mathrm{SnP}: 4.36 \pm 0.81)$ and PWC navigation (TDS: $4.18 \pm 0.75$, TDS: $4.18 \pm 0.87$ ). However, in terms of effectiveness, participants found the TDS more effective than SnP for both PC (TDS: $4.46 \pm 0.67, \mathrm{SnP}: 4.18 \pm$ $0.98)$ and PWC (TDS: $4.64 \pm 0.67, \mathrm{SnP}: 4.45 \pm 0.93$ ). The fact that 55 percent of the participants were regularly using the $\mathrm{SnP}$ for PWC navigation suggests that endusers who start using TDS immediately after their injury may find it both easier and more effective than SnP over long-term use.

The factor loadings for the second factor were 0.88 and 0.72 for PQ21 and PQ22, respectively $(\alpha=0.72)$. Individuals were satisfied with the TDS $(4.56 \pm 0.82)$, and most $(73 \%)$ would have been willing to use the system on a daily basis $(4.00 \pm 1.61)$. The third factor loadings were between 0.65 and 0.82 with $\alpha=0.92$. Except for one person who did not answer these questions, 50 percent preferred the TDS over their current ATs in terms of ease of use $(3.50 \pm 1.27)$ and effectiveness $(3.50 \pm 1.18)$. They also said that the TDS allowed for the control of more functions than their current ATs (4.22 \pm 1.39$)$.

\section{System Improvements (Open-Ended Questions)}

As part of the PSSUQ, participants were asked about (1) the problems they had with the current TDS prototype over the study period and (2) their opinions about how to improve the system. Participants had a chance to respond with three comments to each open-ended question. Their responses were sorted in five categories, as shown in Figure 12(a). Except for one subject who did not comment on or identify any problem, others gave a total of 24 responses to the first question. Seven issues were related to the headgear ( 4 about its appearance and 3 about its mechanical stability). Seven responses were about the system accessibility, including the speed of cursor movement, PWC speed, system calibration, and training. Three were related to the tongue piercing, and three were about the system being limited to interfacing only with certain applications. Finally, there were three responses about technical issues that had happened during the trial.

The second question elicited 20 responses from nine participants (Figure 12(b)). Seven responses were related to the system accessibility; speed of cursor/PWC (3), easier system calibration and training (2), proportional control capability (1), and a request for more 


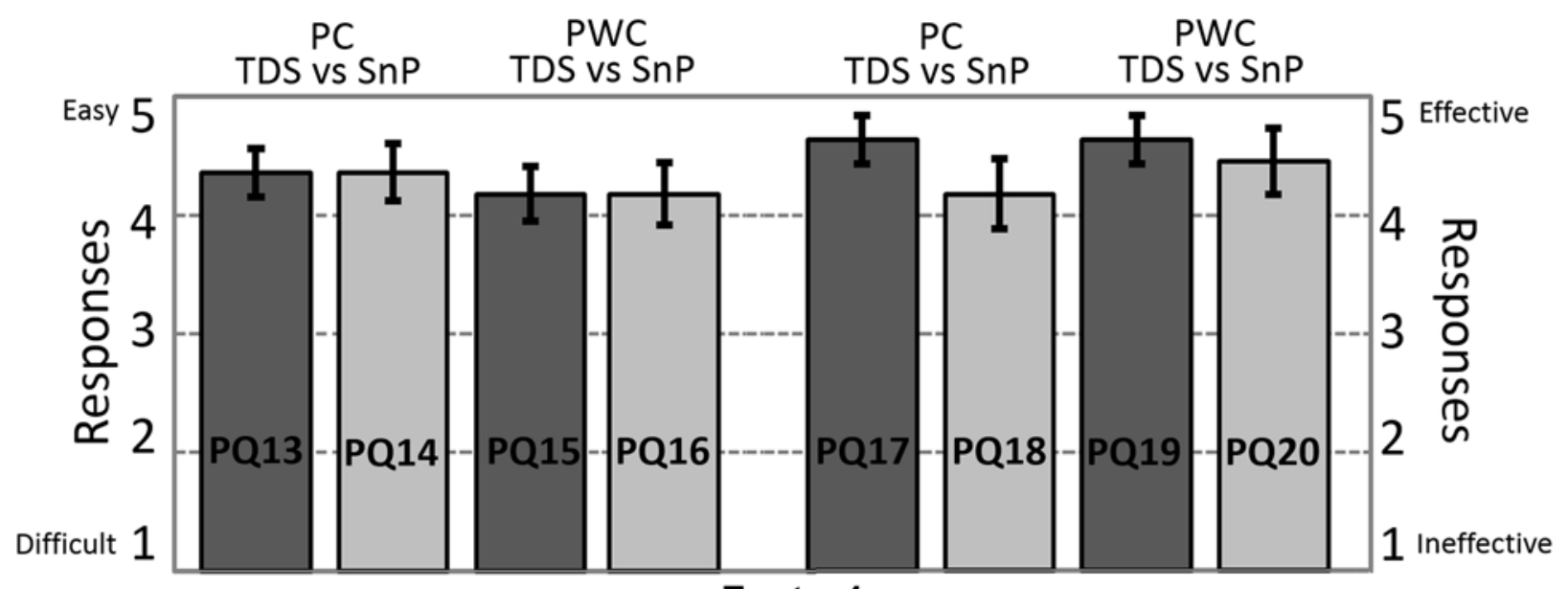

Factor1

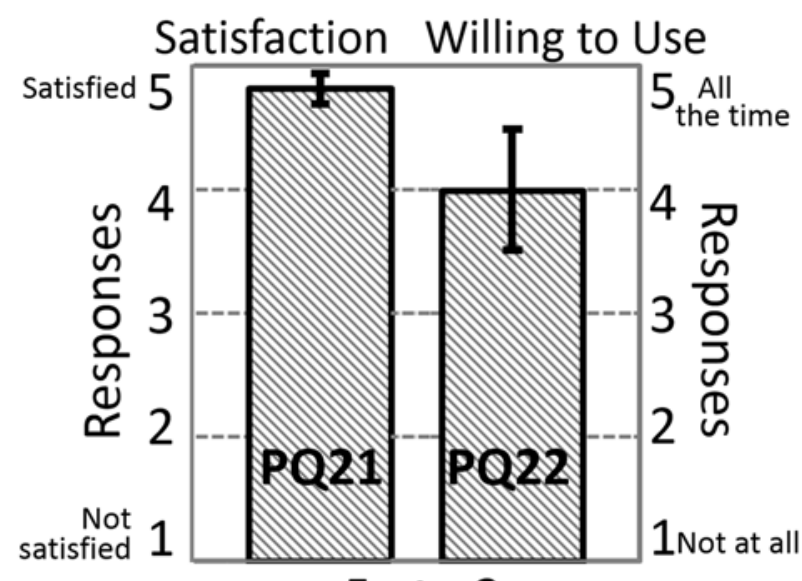

Factor2
Comparison with Current AT

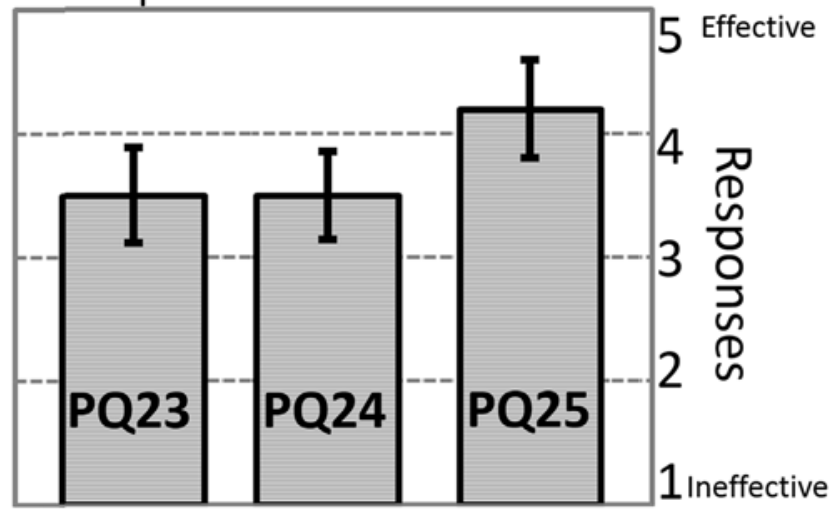

Factor3

Figure 11.

Participants' responses to questions related to usability of Tongue Drive System (TDS) and sip-and-puff (SnP) (factor 1: PQ13PQ20), satisfaction with TDS (factor 2: PQ21 and PQ22), and performance comparison with current assistive technology (AT) (factor 3: PQ23-PQ25). Error bars represent standard error. $P C=$ personal computer, $P Q=$ poststudy system usability questionnaire question, $\mathrm{PW}=$ powered wheelchair.

games (1). Five participants preferred a smaller and better-looking headgear (Figure 1). Four participants suggested that the tongue piercing procedure would be improved by reducing hospital stays (2), optimizing the position of piercing on the tongue (1), and a different size of the barbell (1). Two participants wished to control more applications using the TDS, and another two mentioned that the remaining technical issues (e.g., software "bugs") need to be resolved.

Participants were asked to give further details about how they liked wearing a headgear (external TDS [eTDS]) versus a dental retainer (intraoral TDS [iTDS]) version of the TDS, and whether they preferred a mag- netic tongue barbell over a magnetic implant. Out of 11 participants, 10 preferred the concept of the iTDS, which was under development at the time of this study [21]. One participant stated that he did not know because he had had no experience with the iTDS. Six out of 10 participants who chose the iTDS preferred it to the eTDS because it was less visible.

We explained the differences between the implanted magnetic tracer and the tongue barbell, as well as the planned procedure for implanting it via a hypodermic needle. Five out of 11 participants preferred to have the magnetic implant, four preferred the tongue barbell, one did not have any preference, and one did not answer this question 


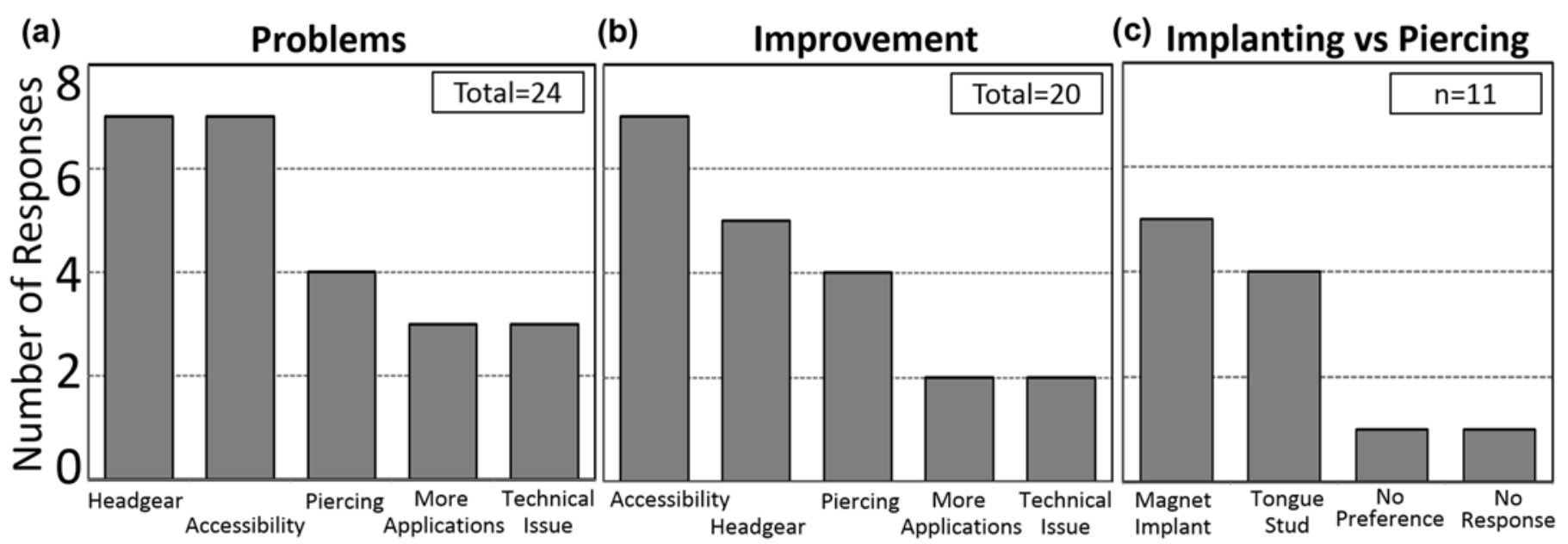

Figure 12.

Participants' responses to open-ended questions about (a) system problems, (b) suggested improvement, and (c) preferred method of attaching magnet to tongue.

(Figure 12(c)). The majority of the participants who preferred the tongue barbell stated that they liked the tongue barbell because it can be removed easily if necessary.

\section{DISCUSSION}

Receiving qualitative feedback from potential end users and caregivers on various aspects of new ATs is a crucial part of the design cycle, particularly for concepts that are difficult to quantify (e.g., comfort and aesthetics). Nevertheless, coverage of the qualitative aspects of new ATs, such as BCIs, in the scientific and technical literature is sparse. The few existing publications are limited to devices already on the market after completion of the design phase, with or without considering the endusers' opinions [2,22]. This issue is critical considering that many ATs, often supported by public and private funds, never leave the laboratory where they are developed, and those that do leave the laboratory are abandoned at alarming rates (35-75\%) [3-4].

Sound qualitative research on new ATs is not easy to conduct. When examining the interactions of new ATs with end users, some of the main complexities include (1) that AT devices being tested are typically functional prototypes and in most cases still far from the polished and professionally designed final products; (2) the small number of participants in each study who meet inclusion criteria and have reliable transportation and caregiver support over the course of the study; (3) geographic distance of the subjects relative to the study centers; (4) the heterogeneity of people with movement disorders/ impairments; (5) the relatively short period of the study, which is often not sufficient for the participants to fully learn, practice, and use all aspects of the new AT, in particular, outside the controlled laboratory or rehabilitation hospital and in their actual home, office, and outdoor environments; (6) the broad range of socioeconomic, educational, ethnic, racial, and vocational backgrounds among end users affecting their prior access, knowledge, and familiarity with the existing ATs and the potential role that technology in general can play in improving quality of life; (7) differences in the periods postinjury or the rate of decline in those with neurodegenerative diseases; and (8) the social network and immediate support that is available to them from immediate family, caregivers, friends, and local community. The present study has been affected by all these limiting factors.

Generally, higher number of samples lead to stronger conclusions in factor analysis, and $n \geq 100$ is preferred [23]. A minimum of five participants is recommended for each variable in Floyd and Widaman [24]. Hence, for our questionnaires and their individual topics, 25 to 65 participants were needed. Simulations in de Winter et al. estimated the minimum number of samples with different levels of factor loadings, number of factors, and number 
of variables for small sample sizes in factor analysis [25]. In this analysis, two thirds of factor loadings of variables were higher than 0.80 and the average factor loading was 0.79 . Considering these parameters, the minimum numbers of samples based on de Winter et al. should be between 18 and 24 for individual questionnaires [25]. However, we only had 11 participants, which is obviously lower than the minimum recommended sample size.

Even though the majority of the participants (70\%) stated that they were not concerned about the appearance of the TDS prototypes used in this study, which were fabricated using headgears (Figure 1), four responders indicated that its appearance was a problem. This reinforces conclusions in literature about the importance of the aesthetic aspects of ATs [5]. This issue was shared in separately run focus groups consisting of a mix of study participants and other individuals with severe physical disabilities who did not participate in the study. It should also be pointed out that the participants in this study might have been a select group who were relatively more excited about prospects of advanced technologies and, therefore, willing to explore new ATs regardless of their appearance.

In response to the questions about participants' preference toward the eTDS, worn as a headset, or the iTDS, worn as a dental retainer, more than 90 percent selected the iTDS as the preferred device. These responses may reflect the fact that participants had already experienced the eTDS prototype with headgear but had only heard a description of the iTDS along with a few rendered images. A more reliable response would require participants to use each version of the TDS over a similar time for performing similar tasks. Nonetheless, a follow-up question offers more insight, in which 60 percent of the participants who chose the iTDS preferred it over the eTDS because it was less likely to be seen by others. Thus, it can be inferred that the TDS appearance does matter to end users, and when offered a choice, they are likely to select the AT that is less visible or entirely invisible to reduce the risk of attracting unsolicited attention or experiencing social stigma.

Similarly, more participants were interested in receiving the magnetic tracer in the form of an implant injected into the tongue rather than a tongue piercing. This outcome, while being in line with the participants' preference for using the completely hidden iTDS rather than the head-worn eTDS, should be considered together with the fact that participants in this study had received a magnetic tongue barbell, but they had only heard about a magnetic tongue implant.

Many problems reflected in the participants' comments are easily addressable in a more refined version of the TDS because, unlike the experimental settings of the TDS, which were kept constant for all participants over the course of the study, they can be customized for each end-user and modified over time as the users become more familiar with the system. For example, the speed of the mouse cursor or PWC can be adjusted easily on the computer and PWC for each user. Also, the duration of system calibration and training can be significantly reduced as the users become fully accustomed to their tongue command positions and capable of issuing them more consistently. With respect to using the TDS for computer access and PWC navigation, the continuous progress of both nondisabled and tetraplegic participants in our broader 5 to $6 \mathrm{wk}$ longitudinal study has been quantitatively measured and well-documented in prior publications [10,14-15].

TDS has the flexibility and utility in accessing and controlling numerous other applications, such as smartphones and home appliances (Figure 1) [10,26]. This study only focused on the qualitative aspects of the PC access and PWC navigation tasks, some of which can be extended to other applications. However, those other devices and applications have specific features and subtleties that, except for smartphones, were neither experienced by the participants nor specifically covered in the questionnaires. Nevertheless, participants were introduced to the potential uses of the TDS in other applications in the initial system overview, and their expectations of being able to do more things with the TDS than with their current AT were reflected in their responses.

It should be noted that the responses to the first group of questions, summarized in Figure 4, which covers the tongue piercing experience, are coming from a subset of individuals with tetraplegia who were either interested in or curious about receiving a tongue piercing and perceived value in using the TDS or participating in the study (e.g., for the advancement of science and technology). Hence, these results do not represent the perception of the general population of people with tetraplegia, some of whom did not volunteer for participation in this study because of the tongue piercing requirement. On the other hand, it was made clear in the recruitment material and to the participants that the present TDS prototype is a device under development, and this would not be available for 
daily use following the trial. Nevertheless, more than 50 percent of the participants stated that they would like to keep their tongue piercing, and 4 out of 11 participants actually did keep their tongue piercings at least 1 mo after completion of TDS experimental procedures. Perhaps if TDS had been commercially available and technically supported after the end of the study, more potential end users would have participated in the study and a higher percentage of them would have kept their magnetic tongue barbells for ongoing use.

Additional research is needed with broader inclusion criteria to determine what percentage of those who could benefit from using the TDS may have been deterred by the minimally invasive tongue piercing procedure. The results of such a study can inform researchers who work on new ATs with far more invasive requirements, such as BCIs that need implantation of intracranial electrodes via brain surgery [26-28], about acceptability of advanced technologies among the end-user population.

\section{CONCLUSIONS}

We have developed a wireless and wearable tongueoperated AT in order to provide reliable, easy, and effective accesses to PCs, PWCs, smartphones, and other devices in the users' environments. This study focused on subjective assessment of the TDS by a high-level SCI cohort who received magnetic tongue piercings in order to use the system for PC access and PWC navigation over 6 wk. Overall, participants had no major issues with the tongue piercing, and more than 70 percent would have been willing to keep a tongue barbell for ongoing use of the system. More than 60 percent of participants had no concerns about the appearance of the headgear, and $\sim 50$ percent of participants said that the TDS was easy to access. Moreover, the TDS performance was considered satisfactory by participants at the end of the study, with half of the users assessing the TDS as more effective than the SnP and their current ATs despite their brief experience with the TDS. We plan to include more specific questions to explore each factor more thoroughly and recruit a broader end-user population in our future qualitative studies. A larger population will allow categorization of participants' responses for further analysis by age; sex; education; socioeconomic status; support network; and duration, type, and severity of the movement impairment, disorder, or amputation. Moreover, the results of this and subsequent studies will be used to help improve the TDS technology and its variations.

\section{ACKNOWLEDGMENTS}

\section{Author Contributions:}

Study concept and design: M. Ghovanloo, D. P. West, E. Roth, A. E. Laumann.

Acquisition of data: J. Kim, H. Park, J. Bruce, D. Rowles, J. Holbrook, B. Nardone.

Analysis and interpretation of data: J. Kim, E. Veledar, M. Ghovanloo. Drafting of the manuscript: J. Kim, M. Ghovanloo.

Statistical analysis: J. Kim, E. Veledar.

Critical revision of manuscript for important intellectual content:

M. Ghovanloo, A. E. Laumann.

Obtained funding: M. Ghovanloo, A. E. Laumann, E. Roth, D. P. West. Administrative, technical, or material support: M. Ghovanloo, A. E. Laumann.

Study supervision: M. Ghovanloo, A. E. Laumann.

Financial Disclosures: Dr. Ghovanloo is the founder of a startup company, Bionic Sciences Inc, which was formed to bring the TDS to market. The company was formed after completion of this study and has had no sponsorship role in any aspect of this article. Dr. Ghovanloo, as the principle investigator of the study, has been involved in all the aforementioned aspects of the study and this article.

Funding/Support: This material was based on work supported by the National Institute of Biomedical Imaging and Bioengineering (grant 1RC1EB010915) and the National Science Foundation (awards IIS0953107 and CBET-0828882).

Additional Contributions: We would like to thank Pride Mobility Inc for donating two Quantum 6000 PWSs for this study. We would also like to thank all participants in this study for their time and valuable feedback.

Institutional Review: All participants provided informed consent to the procedures approved by the institutional review boards of record at SCA and NU.

Participant Follow-Up: The authors will inform the participants who are still in touch. They have no plans to notify the other study subjects of the publication of this article because of lack of contact information.

\section{REFERENCES}

1. Christopher and Dana Reeve Foundation. One degree of separation: Paralysis and spinal cord injury in the United States [Internet]. Short Hills (NJ): Christopher and Dana Reeve Foundation; 2009. Available from: http://www.christopherreeve.org/site/c.ddJFKRNoFiG/ b.5091685/k.58BD/One_Degree of Separation.htm

2. Cook AM, Polgar JM. Cook and Hussey's assistive technologies: Principles and practice. 3rd ed. St. Louis (MO): Mosby Elsevier; 2008. 
3. Martin B, McCormack L. Issues surrounding assistive technology use and abandonment in an emerging technological culture. In: Bühler C, Knops H, editors. Assistive technology on the threshold of a new millennium. Washington (DC): IOS Press; 1999. p. 413-20.

4. Riemer-Reiss ML, Wacker RR. Factors associated with assistive technology discontinuance among individuals with disabilities. J Rehabil. 2000;66(3):44-50.

5. Parette P, Scherer M. Assistive technology use and stigma. Educ Train Dev Disabil. 2004;39(3):217-26.

6. Anderson KD. Targeting recovery: Priorities of the spinal cord-injured population. J Neurotrauma. 2004;21(10): 1371-83. [PMID:15672628]

http://dx.doi.org/10.1089/neu.2004.21.1371

7. Snoek GJ, IJzerman MJ, Hermens HJ, Maxwell D, BieringSorensen F. Survey of the needs of patients with spinal cord injury: Impact and priority for improvement in hand function in tetraplegics. Spinal Cord. 2004;42(9):526-32. [PMID:15224087] http://dx.doi.org/10.1038/sj.sc.3101638

8. Collinger JL, Boninger ML, Bruns TM, Curley K, Wang W, Weber DJ. Functional priorities, assistive technology, and brain-computer interfaces after spinal cord injury. J Rehabil Res Dev. 2013;50(2):145-60. [PMID:23760996] http://dx.doi.org/10.1682/JRRD.2011.11.0213

9. Huo X, Wang J, Ghovanloo M. A magneto-inductive sensor based wireless tongue-computer interface. IEEE Trans Neural Syst Rehabil Eng. 2008;16(5):497-504. [PMID:18990653] http://dx.doi.org/10.1109/TNSRE.2008.2003375

10. Huo X, Wang J, Ghovanloo M. Introduction and preliminary evaluation of the Tongue Drive System: Wireless tongue-operated assistive technology for people with little or no upper-limb function. J Rehabil Res Dev. 2008; 45(6):921-30. [PMID:19009478] http://dx.doi.org/10.1682/JRRD.2007.06.0096

11. Kim J, Huo X, Minocha J, Holbrook J, Laumann A, Ghovanloo M. Evaluation of a smartphone platform as a wireless interface between tongue drive system and electric-powered wheelchairs. IEEE Trans Biomed Eng. 2012;59(6):1787-96. [PMID:22531737] http://dx.doi.org/10.1109/TBME.2012.2194713

12. Sadeghian EB, Huo X, Ghovanloo M. Command detection and classification in tongue drive assistive technology. Conf Proc IEEE Eng Med Biol Soc. 2011;2011:5465-68. [PMID:22255574]

13. Huo X, Ghovanloo M. Evaluation of a wireless wearable tongue-computer interface by individuals with high-level spinal cord injuries. J Neural Eng. 2010;7(2):26008. [PMID:20332552] http://dx.doi.org/10.1088/1741-2560/7/2/026008
14. Yousefi B, Huo X, Veledar E, Ghovanloo M. Quantitative and comparative assessment of learning in a tongue-operated computer input device. IEEE Trans Inf Technol Biomed. 2011;15(5):747-57. [PMID:21652288] http://dx.doi.org/10.1109/TITB.2011.2158608

15. Yousefi B, Huo X, Kim J, Veledar E, Ghovanloo M. Quantitative and comparative assessment of learning in a tongue-operated computer input device-part II: Navigation tasks. IEEE Trans Inf Technol Biomed. 2012;16(4): 633-43. [PMID:22692932] http://dx.doi.org/10.1109/TITB.2012.2191793

16. Lewis JR. IBM computer usability satisfaction questionnaires: Psychometric evaluation and instructions for use. Int J Hum Comput Interact. 1995;7(1):57-78. http://dx.doi.org/10.1080/10447319509526110

17. Lewis JR. Psychometric evaluation of the PSSUQ using data from five years of usability studies. Int J Hum Comput Interact. 2002;14(3-4):463-88. http://dx.doi.org/10.1080/10447318.2002.9669130

18. Minocha JS, Holbrook JS, West DP, Ghovanloo M, Laumann AE. Development of a tongue-piercing method for use with assistive technology. JAMA Dermatol. 2014; 150(4):453-54. [PMID:24284925] http://dx.doi.org/10.1001/jamadermatol.2013.7165

19. Bangor A, Kortum PT, Miller JT. An empirical evaluation of the system usability scale. Int J Hum Comput Interact. 2008;24(6):574-94. http://dx.doi.org/10.1080/10447310802205776

20. Huo X, Ghovanloo M. Using unconstrained tongue motion as an alternative control mechanism for wheeled mobility. IEEE Trans Biomed Eng. 2009;56(6):1719-26. [PMID:19362901] http://dx.doi.org/10.1109/TBME.2009.2018632

21. Park H, Kiani M, Lee HM, Kim J, Block J, Gosselin B, Ghovanloo M. A wireless magnetoresistive sensing system for an intraoral tongue-computer interface. IEEE Trans Biomed Circuits Syst. 2012;6(6):571-85.

[PMID:23853258] http://dx.doi.org/10.1109/TBCAS.2012.2227962

22. Caltenco HA, Breidegard B, Jönsson B, Andreasen Struijk LN. Understanding computer users with tetraplegia: Survey of assistive technology users. Int J Hum Comput Interact. 2012;28(4):258-68. http://dx.doi.org/10.1080/10447318.2011.586305

23. MacCallum RC, Widaman KF, Zhang S, Hong S. Sample size in factor analysis. Psychol Methods. 1999;4(1):84-99. http://dx.doi.org/10.1037/1082-989X.4.1.84

24. Floyd FJ, Widaman KF. Factor analysis in the development and refinement of clinical assessment instruments. Psychol Assess. 1995; 7(3):286-99. http://dx.doi.org/10.1037/1040-3590.7.3.286 
25. de Winter JC, Dodou D, Wieringa PA. Exploratory factor analysis with small sample sizes. Multivariate Behav Res. 2009;44(2):147-81.

http://dx.doi.org/10.1080/00273170902794206

26. Hochberg LR, Bacher D, Jarosiewicz B, Masse NY, Simeral JD, Vogel J, Haddadin S, Liu J, Cash SS, van der Smagt P, Donoghue JP. Reach and grasp by people with tetraplegia using a neurally controlled robotic arm. Nature. 2012;485(7398):372-75. [PMID:22596161] http://dx.doi.org/10.1038/nature11076

27. Collinger JL, Wodlinger B, Downey JE, Wang W, TylerKabara EC, Weber DJ, McMorland AJ, Velliste M, Boninger ML, Schwartz AB. High-performance neuroprosthetic control by an individual with tetraplegia. Lancet. 2013;381(9866):557-64. [PMID:23253623] http://dx.doi.org/10.1016/S0140-6736(12)61816-9

28. Lee B, Liu CY, Apuzzo ML. A primer on brain-machine interfaces, concepts, and technology: A key element in the future of functional neurorestoration. World Neurosurg. 2013;79(3-4):457-71. [PMID:23333985] http://dx.doi.org/10.1016/j.wneu.2013.01.078
Submitted for publication August 8, 2013. Accepted in revised form November 6, 2013.

This article and any supplementary material should be cited as follows:

Kim J, Park H, Bruce J, Rowles D, Holbrook J, Nardone B, West DP, Laumann AE, Roth E, Veledar E, Ghovanloo M. Qualitative assessment of Tongue Drive System by people with high-level spinal cord injury. J Rehabil Res Dev. 2014;51(3):451-66.

http://dx.doi.org/10.1682/JRRD.2013.08.0178

ResearcherID/ORCID: Maysam Ghovanloo, PhD: D8343-2014

\begin{tabular}{|c|c|}
\hline 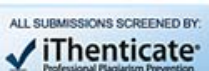 & ef НЕнвЕ \\
\hline 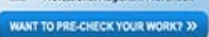 & $\begin{array}{l}\text { CROSSREF.ORG } \\
\text { THE CITATIOH LINKING BACKEONE }\end{array}$ \\
\hline
\end{tabular}


